Jpn. J. Med. Mycol.

Vol. 47, 225-229, 2006

ISSN $0916-4804$

Original Article

\title{
A One-Enzyme PCR-RFLP Assay for Identification of Six Medically Important Candida Species
}

\author{
Hossein Mirhendi ${ }^{1}$, Koichi Makimura ${ }^{2}$, Mohamadreza Khoramizadeh ${ }^{3}$, \\ Hideyo Yamaguchi ${ }^{2}$ \\ ${ }^{1}$ Department of Medical Parasitology and Mycology, School of Public Health and Institute of \\ Public Health Researches (Esfahan Center), Tehran University of Medical Sciences, Tehran, IRAN \\ ${ }^{2}$ Institute of Medical Mycology and Genome Research Center, Teikyo University, \\ 359 Otsuka, Hachioji, Tokyo 192-0395, Japan \\ ${ }^{3}$ Department of Pathobiology, School of Public Health, Tehran University of Medical Sciences, Tehran, IRAN
}

[Received: 17, November 2005. Accepted: 17, April 2006]

\begin{abstract}
Early identification of Candida isolates to the species level is necessary for effective antifungal therapy, and can also facilitate control of hospital infections. Phenotype-based methods for identifying Candida species are often difficult and time-consuming. Molecular biological techniques provide a useful alternative approach. In the present study, the ITS1-5.8S-ITS2 regions of fungal rRNA genes were amplified with universal primers in 20 standard strains. Digestion of the PCR products with one restriction enzyme, Msp I, allowed discrimination of medically important Candida species, including C. albicans, C. glabrata, C. parapsilosis, C. tropicalis, C. krusei, and C. guilliermondii. Using this method, we successfully identified 137 clinical isolates of Candida. Among them, $C$. albicans was identified as the most common species, followed by C. parapsilosis, C. tropicalis, $C$. glabrata, C. krusei, and C. guilliermondii. This method is a simple, rapid, and cost-effective method for differentiation between species that is applicable in clinical laboratories.
\end{abstract}

Key words: Candida, PCR, RFLP, MspI, identification

\section{Introduction}

Candida species are considered a major cause of opportunistic infections in humans. In recent years, despite advances in health care and therapeutic methods, the incidence of invasive systemic candidiasis has increased markedly. This is thought to be the result of the increase in size of populations at risk, such as transplant recipients, cancer patients, HIV-infected patients, and those receiving immunosuppressive and broad-spectrum antibiotic therapy ${ }^{1-3)}$. Although the majority of Candida infections are caused by C. albicans, non-albicans species of Candida, such as C. glabrata and C. krusei, which are less susceptible to azoles derivatives have been

Corresponding author: Hossein Mirhendi, PhD.

epartment of Medical Parasitology and Mycology, School of Public Health, Tehran University of Medical Sciences, Tehran, 14155-6446, IRAN reported with increasing frequency ${ }^{4,5)}$. Early diagnosis of invasive fungal infections is essential to reduce the mortality rates. In addition, identification of species is essential for effective antifungal therapy with regard to the emergence of resistance to antifungal drugs. Although Candida identification kits based on assimilation tests are commercially available, these kits require at least 1 to 5 days for identification of Candida at the species level. Recently, molecular techniques have provided alternative methods for diagnosis and identification of pathogenic fungi, including Candida species ${ }^{6,7)}$. Molecular methods with high discriminatory power are required for reliable identification of Candida at the species level, especially in epidemiological studies to assess the transmission routes as well as to determine appropriate antifungal drugs ${ }^{8-10)}$. Although various methods have been reported for molecular identification of Candida spp., 
such as RAPD (random amplified polymorphic DNA)-PCR, DNA sequence analysis, and mitochondrial large subunit ribosomal RNA gene sequencing ${ }^{11,12)}$, these tests are still timeconsuming and too expensive for routine use, especially in medical laboratories. Here, we report the application of a rapid PCR-based technique using a one-enzyme restriction fragment length polymorphism (RFLP), for discrimination of six clinically important Candida species.

\section{Materials and Methods}

Strains: Standard strains, which were provided by Teikyo University Institute of Medical Mycology (TIMM), Tokyo, Japan, are listed in Table 1. In addition, 137 clinical isolates from the Medical Mycology Laboratory, Tehran University of Medical Sciences, Iran, were also used. All yeasts were cultured on Sabauroud's dextrose agar and incubated at $32^{\circ} \mathrm{C}$ for two days. All clinical isolates were also cultured on CHROMagar Candida (Kanto Chemical Co., Ltd., Tokyo) and incubated at $35^{\circ} \mathrm{C}$ for $48 \mathrm{~h}$ for production of species-specific colors.

DNA extraction: Genomic DNA was extracted and purified using glass bead disruption ${ }^{13)}$. Briefly, a loop full of fresh yeast was harvested and suspended in $300 \mu l$ of lysis buffer (10 $\mathrm{mM}$ Tris, $1 \mathrm{mM}$ EDTA pH 8, 1\% SDS, $100 \mathrm{mM}$
$\mathrm{NaCl}, 2 \%$ Triton X-100). After adding $300 \mu l$ of phenol-chloroform $(1: 1)$ and $300 \mathrm{mg}$ of glass beads $(0.5 \mathrm{~mm}$ in diameter $)$, samples were vortexed vigorously for $5 \mathrm{~min}$ to disrupt the cells completely. Cellular debris was separated by centrifugation at $10,000 \mathrm{rpm}$ for $5 \mathrm{~min}$ and the aqueous layer was extracted once more with an equal volume of chloroform. Total DNA in the supernatant was precipitated with 2propanol, washed with $70 \%$ ethanol, air-dried, resuspended in $100 \mu l$ of TE buffer $(10 \mathrm{mM}$ Tris, $1 \mathrm{mM}$ EDTA), and preserved at $-20^{\circ} \mathrm{C}$ until use.

PCR conditions: PCR amplification was carried out in a final volume of $100 \mu l$. Each reaction contained $1 \mu l$ of template DNA, each forward (ITS1, 5'-TCG GTA GGT GAA CCT GCG G-3') and reverse (ITS4, 5'-TCC TCC GCT TAT TGA TAT GC-3') primer at $0.2 \mu \mathrm{M}$, each deoxynucleoside triphosphate (dNTP) at $0.1 \mathrm{mM}, 10 \mu \mathrm{l}$ of $10 \times$ PCR buffer, and $2.5 \mathrm{U}$ of Taq DNA polymerase. An initial denaturation step at $94^{\circ} \mathrm{C}$ for $5 \mathrm{~min}$ was followed by 25 cycles of denaturation at $94^{\circ} \mathrm{C}$ for $30 \mathrm{~s}$, annealing at $56^{\circ} \mathrm{C}$ for $45 \mathrm{~s}$, and extension at $72^{\circ} \mathrm{C}$ for $1 \mathrm{~min}$, with a final extension step of $72^{\circ} \mathrm{C}$ for $7 \mathrm{~min}$. Amplified products were visualized by $1.5 \%(\mathrm{w} / \mathrm{v})$ agarose gel electrophoresis in TBE buffer (0.09 M Tris, $0.09 \mathrm{M}$ boric acid, and $20 \mathrm{mM}$ EDTA, pH 8.3),

Table 1. Standard yeast strains used in the present study

\begin{tabular}{ll}
\hline \multicolumn{1}{c}{ Species } & \multicolumn{1}{c}{ Strains } \\
\hline Candida albicans & ATCC 10261, ATCC 10231, ATCC 24432, TIMM 1768 \\
C. glabrata & ATCC 90030, CBS 138 \\
C. tropicalis & ATCC 0750, TIMM 0313 \\
C. krusei & ATCC 6258, TIMM 3404 \\
C. parapsilosis & ATCC 22019, ATCC 90018 \\
C. guilliermondii & ATCC 9058, TIMM 0257 \\
C. albicans var. stellatoidea & TIMM 1309 \\
C. dubliniensis & CBS 7987 \\
Cryptococcus neoformans & ATCC 90113 \\
Saccharomyces cerevisiae & ATCC 9763, ATCC 2366 \\
Trichosporon asahii & TIMM 3411
\end{tabular}

Table 2. Sizes of ITS1-ITS4 PCR products for Candida species before and after digestion with Msp I

\begin{tabular}{lccc}
\hline Candida species & $\begin{array}{c}\text { Size of } \\
\text { ITS1-ITS4 }\end{array}$ & $\begin{array}{c}\text { Size (s) of restriction } \\
\text { product(s) }\end{array}$ & $\begin{array}{c}\text { *Accession } \\
\text { number }\end{array}$ \\
\hline C. albicans & 535 & 297,238 & L47111 \\
C. glabrata & 871 & 557,314 & AF167993 \\
C. tropicalis & 524 & 340,184 & L47112 \\
C. krusei & 510 & 261,249 & L47113 \\
C. guilliermondii & 608 & $371,155,82$ & L47110 \\
C. parapsilosis & 520 & 520 & L47109 \\
\hline
\end{tabular}

*DDBG/EMBL/GenBank accession number 
stained with ethidium bromide $\left(0.5 \mu \mathrm{g} \mathrm{m} l^{-1}\right)$, and photographed.

RFLP analysis: The ITS1-ITS4 sequences of various Candida species obtained from DDBJ/ EMBL/GenBank databases were aligned and restriction patterns of the PCR products of the species mentioned above were predicted for each of the known restriction enzymes using DNASIS software (Hitachi Software Engineering Co., Tokyo). Predicted restriction fragments were compared to choose the best discrimination. Finally, the enzyme $M s p$ I was selected to achieve the best species-specific length patterns as shown in Table 2. Digestion was performed by incubating a 20- $\mu l$ aliquot of PCR product with $10 \mathrm{U}$ of Msp I (Roche Molecular, Mannhiem, Germany) in a final reaction volume of $25 \mu l$ at $37^{\circ} \mathrm{C}$ for $2 \mathrm{~h}$. Restriction fragments were separated by $1.8 \%$ agarose gel electrophoresis in TBE buffer for approximately $45 \mathrm{~min}$ at 100 $\mathrm{V}$ and visualized by staining with ethidium bromide.

\section{Results}

Fungus-specific universal primer pairs (ITS1 and ITS4) were able to successfully amplify the ITS region of all yeasts tested, providing a single PCR product of approximately 510 870 bp (Fig. 1). After analysis of various restriction enzymes, Msp I was selected as the best enzyme

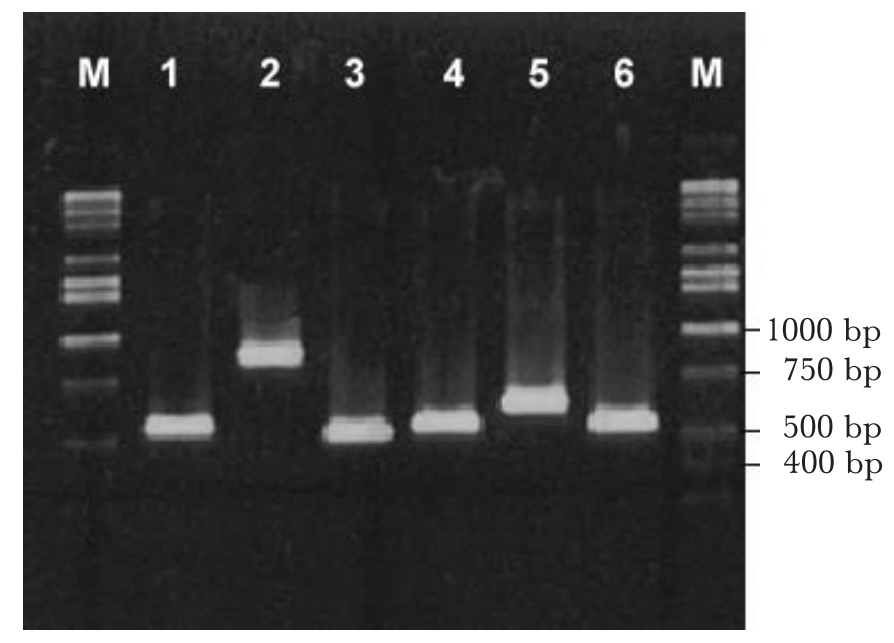

Fig. 1. PCR products from six Candida species. Lanes 1-6: C. albicans (ATCC 10261), C. glabrata (ATCC 90030), C. tropicalis (ATCC 0750), C. krusei (ATCC 6258), C. guilliermondii (ATCC 9058) and C. parapsilosis (ATCC 22019), respectively. Lanes M: Molecular size marker
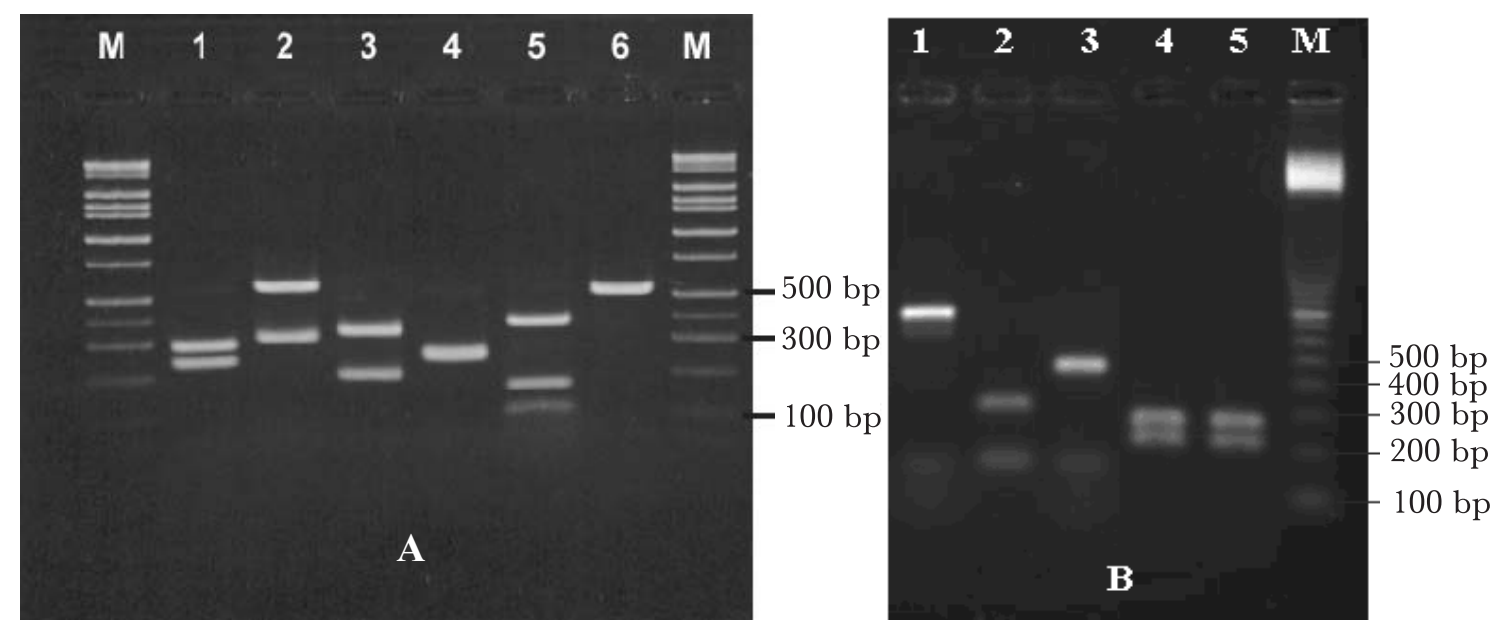

Fig. 2. A) Restriction digestion of PCR products of Candida strains with the enzyme Msp I. Lanes 1-6: C. albicans (ATCC 10261), C. glabrata (ATCC 90030), C. tropicalis (ATCC 0750), C. krusei (ATCC 6258), C. guilliermondii (ATCC 9058) and C. parapsilosis (ATCC 22019), respectively. Lane M: molecular size marker. B) Restriction digestion of PCR products of other strains with the enzyme Msp I. Lanes 1-5: S. cerevisiae (ATCC 9763), T. asahii (TIMM 3411), C. neoformans (ATCC 90113), C. albicans var. stellatoidea (TIMM1309) and C. dubliniensis (CBS 7987), respectively. Lane M: Molecular size marker 
Table 3. Identification of clinical isolates of Candida species in Iran by PCR-RFLP amplification of the ITS1-ITS4 region and RFLP analysis with $M s p$ I

\begin{tabular}{lcc}
\hline \multicolumn{1}{c}{ Species } & Number & $\%$ \\
\hline C.albicans and/or C. dubliniensis & 93 & 67.9 \\
C. tropicalis & 12 & 8.8 \\
C. parapsilosis & 12 & 8.8 \\
C. glabrata & 9 & 6.6 \\
C. krusei & 7 & 5.1 \\
C. guilliermondii & 4 & 2.9 \\
\hline Total & 137 & 100 \\
\hline
\end{tabular}

for differentiation between six medically important Candida species. PCR amplicons were digested with $M s p \mathrm{I}$ as described in Materials and Methods. The products of digestion are shown separately in Fig. 2, which shows that the bands generated corresponded to the predicted sizes. Digestion of the ITS region of Candida species by $M s p$ I generated 2 bands for C. albicans, $C$. glabrata, C. tropicalis, and C. krusei, and 3 bands for C. guilliermondii. However, there were no recognition sites for this enzyme within the ITS region of $C$. parapsilosis, and its PCR and digestion products were the same size.

The RFLP pattern produced for each Candida species was completely specific so none of the species examined was mistaken for another (Fig 2, A). Identical patterns were seen for C. albicans, C. albicans var. stellatoidea, and C. dubliniensis (Fig2, B). None of the other yeasts tested, including Cryptococcus neoformans, Saccharomyces cerevisiae, and Trichosporon asahii, showed similar patterns (Fig2, B). The enzyme was also used for digestion of PCR products of 137 strains of Candida isolated from clinical specimens, including superficial, mucocutaneous, and deep seated specimens. Using this method, C. albicans was identified as the most common species $(67.9 \%)$ followed by C. parapsilosis, C. tropicalis, $C$. glabrata, and C. krusei (Table 3). In our study the results of PCR-RFLP tests for identification of the clinical isolates were completely identical to those obtained using CHROMagar Candida.

\section{Discussion}

Despite recent progress in the development of new molecular approaches for diagnosis of fungal infections, the goal of developing a simple, rapid, and cost effective test for diagnostic purposes remains elusive. In the present study, using the universal primers, ITS1 and ITS4, we amplified a fragment of 510-879 bp of the ITS1-5.8S-ITS2 rDNA region from genomic DNA of several strains of Candida species.
Restriction fragment length polymorphism (RFLP) analysis of the PCR products with one enzyme allowed us to identify the 6 most medically important Candida species.

The ITS molecule contains several regions of highly conserved sequence useful for obtaining proper sequence alignments, but with sufficient sequence variability in other regions of the molecule that can serve as markers of speciesspecific restriction fragment length polymorphism (RFLP) ${ }^{14)}$. This region has been used in part or completely by other investigators for species identification of some medically important fungi, particularly Candida $\left.{ }^{15}, 16\right)$, Aspergillus ${ }^{17)}$, dermatophytes ${ }^{18)}$, Trichosporon ${ }^{19)}$, and Malassezia ${ }^{20)}$ species using various approaches, such as DNA probes, nested PCR, sequencing, and RFLP. Williams et $a l .{ }^{15)}$ attempted to delineate medically important Candida species using restriction enzyme digestion (Hae III, Dde I, Bfa I) after amplification of the ITS1-ITS4 region, but their patterns were not suitable for identification, perhaps due to inaccessibility of related ITS1-ITS4 sequences. Maiwald et al. ${ }^{21}$ ) introduced a method for presumptive differentiation of 12 clinically relevant yeasts to the species level by amplification of the small ribosomal subunit 18S-rRNA using six enzymes. Identification of Candida species by PCR-RFLP has also been applied recently by Deak and Pinto ${ }^{22,}{ }^{23)}$. While all of the mentioned studies discriminated Candida species using several restriction enzymes, we identified six species, which accounts for up to $95 \%$ of Candida infections, using only one enzyme.

In the present study, restriction digestion of the ITS amplification product with Msp I produced the predicted specific patterns for each species. Using this method, all standard stains were identified successfully. Moreover, the results of PCR-RFLP analysis of the clinical isolates examined were comparable with those obtained by CHROMagar Candida test. Unfortunately, digestion of $C$. albicans and $C$. dubliniensis with $M s p$ I yielded similar patterns, and therefore additional enzymes for differentiation of these species are still required. Actually we have reported another PCR-restriction enzyme format for discrimination of these two Candida species ${ }^{24)}$.

We recommend this simple and easy-to-perform method for the identification of Candida isolates in the medical mycology laboratories.

\section{Acknowledgments}

We would like to thank Dr. M Fasihi and Mrs. Kh Omidi for their help. 


\section{References}

1) Fridkin SK, Jarvis WR: Epidemiology of nosocomial fungal infections. Clin Microbiol Rev 9: 499511, 1996.

2) Jarvis WR: Epidemiology of nosocomial fungal infections, with emphasis on Candida species. Clin Infect Dis 20: 1526-1530, 1995.

3) Wenzel RP: Nosocomial candidemia: risk factors and attributable mortality. Clin Infect Dis 20: 1531-1534, 1995.

4) Wingard JR: Importance of Candida species other than C. albicans as pathogens in oncology patients. Clin Infect Dis 20: 115-125, 1995.

5) Nguyen $\mathrm{MH}$, Peacock JE, Morris AJ, Tanner DC, Nguyen ML, Snydman DR, Wagener MM, Rinaldi MG, Yu VL: The changing face of candidemia: emergence of non-Candida albicans species and antifungal resistance. Am J Med 100: 617-623, 1996.

6) Reiss E, Tanaka K, Bruker G, Chazalet V, Coleman D, Debeaupuis JP, Hanazawa R, Latge JP, Lortholary J, Makimura K, Morrison CJ, Murayama SY, Naoe S, Paris S, Sarfati J, Shibuya K, Sullivan D, Uchida K, Yamaguchi $\mathrm{H}$ : Molecular diagnosis and epidemiology of fungal infections. Med Mycol 36 (Suppl 1): 249 $-257,1998$.

7) Yeo SF, Wong B: Current status of nonculture methods for diagnosis of invasive fungal infections. Clin Microbiol Rev 15: 465-484, 2002.

8) Elie CM, Lott TJ, Reiss E, Morrison CJ: Rapid identification of Candida species with speciesspecific DNA probes. J Clin Microbiol 36: 3260 $-3265,1998$.

9) Jordan JA: PCR identification of four medically important Candida species by using a single primer pair. J Clin Microbiol 32: 2962-2967, 1994.

10) Haynes KA, Westerneng TJ: Rapid identification of Candida albicans, C. glabrata, C. parapsilosis and C. krusei by species-specific PCR of large subunit ribosomal DNA. J Med Microbiol 44: 390-396, 1996.

11) Yamada Y, Makimura K, Uchida K, Yamaguchi $\mathrm{H}$, Osumi M: Phylogenetic relationships among medically important yeasts based on sequences of mitochondrial large subunit ribosomal RNA gene. Mycoses 47: 24-28, 2004.

12) Sugita $T$, Nishikawa A: Molecular taxonomy and identification of pathogenic fungi based on DNA sequence analysis. Nippon Ishinkin Gakkai Zasshi 45: 55-58, 2004. (in Japanese)

13) Yamada Y, Makimura K, Mirhendi H, Ueda K, Nishiyama Y, Yamaguchi H, Osumi M: Comparison of different methods for extraction of mitochondrial DNA from human pathogenic yeasts. Jpn J Infect Dis 55: 122-125, 2002.
14) Iwen PC, Hinrichs SH, Rupp ME: Utilization of the internal transcribed spacer regions as molecular targets to detect and identify human fungal pathogens. Med Mycol 40: 87-109, 2002.

15) Williams DW, Wilson MJ, Lewis MA, Potts AJ: Identification of Candida species by PCR and restriction fragment length polymorphism analysis of intergenic spacer regions of ribosomal DNA. J Clin Microbiol 33: 2476-2479, 1995.

16) Chen YC, Eisner JD, Kattar MM, RassoulianBarrett SL, LaFe K, Yarfitz SL, Limaye AP, Cookson BT: Identification of medically important yeasts using PCR-based detection of DNA sequence polymorphisms in the internal transcribed spacer 2 region of the rRNA genes. J Clin Microbiol 38: 2302-2310, 2000.

17) Henry $\mathrm{T}$, Iwen PC, Hinrichs SH: Identification of Aspergillus species using internal transcribed spacer regions 1 and 2. J Clin Microbiol 38: 1510-1515, 2000.

18) Makimura K, Tamura $Y$, Mochizuki T, Hasegawa A, Tajiri Y, Hanazawa R, Uchida K, Saito H, Yamaguchi H: Phylogenetic classification and species identification of dermatophyte strains based on DNA sequences of nuclear ribosomal internal transcribed spacer 1 regions. J Clin Microbiol 37: 920-924, 1999.

19) Sugita T, Nishikawa A, Ikeda R, Shinoda T: Identification of medically relevant Trichosporon species based on sequences of internal transcribed spacer regions and construction of a database for Trichosporon identification. J Clin Microbiol 37: 1985-1993, 1999.

20) Makimura K, Tamura Y, Kudo M, Uchida K, Saito H, Yamaguchi H: Species identification and strain typing of Malassezia species stock strains and clinical isolates based on the DNA sequences of nuclear ribosomal internal transcribed spacer 1 region. J Med Microbiol 49: 29-35, 2000.

21) Maiwald M, Kappe R, Sonntag HG: Rapid presumptive identification of medically relevant yeasts to the species level by polymerase chain reaction and restriction enzyme analysis. J Med Vet Mycol 32: 115-122, 1994.

22) Deak R, Bodai L, Aarts HJ, Maraz A: Development of a novel, simple and rapid molecular identification system for clinical Candida species. Med Mycol 42: 311-318, 2004.

23) Pinto PM, Resende MA, Koga-Ito CY, Ferreira JA, Tendler M: rDNA-RFLP identification of Candida species in immunocompromised and seriously diseased patients. Can J Microbiol 50: 514-520, 2004.

24) Mirhendi H, Makimura K, Zomorodian K, Maeda $\mathrm{N}$, Ohshima T, Yamaguchi $\mathrm{H}$ : Differentiation of Candida albicans and Candida dubliniensis using a single PCR-Restriction enzyme. Jpn J Infect Dis 58: 235-257, 2005. 